\title{
CARACTERIZAÇÃO DA GLICERINA PROVENIENTE DA PRODUÇÃO DE BIODIESEL POR TRANSESTERIFICAÇÃO ETÍLICA DO ÓLEO DE SOJA BRUTO
}

\author{
L. F. dos SANTOS ${ }^{1}$, J. F. MEDEIROS ${ }^{1}$, V. Y. KAJIHARA ${ }^{1}$, N. C. PEREIRA ${ }^{1}$ e O. C. M. \\ LIMA $^{1}$ \\ ${ }^{1}$ Universidade Estadual de Maringá, Departamento de Engenharia Química \\ E-mail para contato: 1fs.francisco.95@gmail.com
}

\begin{abstract}
RESUMO - O biodiesel é uma fonte de energia limpa, renovável e vem sendo cada vez mais aplicado como fonte energética. Consequentemente, está ocorrendo um aumento da produção de glicerina, que é o subproduto da produção de biodiesel. Com esse aumento da oferta de glicerina no mercado são necessárias novas formas de purificações a fim de diminuir seu custo de produção. Portanto, para se escolher a melhor forma de purificação é necessário conhecer melhor a glicerina: saber quais as impurezas presentes nela e quais fatores deverão ser corrigidos. Com base nisso, o presente trabalho tem como objetivo a caracterização da glicerina oriunda da transesterificação etílica do óleo de soja bruto visando o conhecimento das características que necessitam ser melhoradas a fim de atingir um potencial analítico.
\end{abstract}

\section{INTRODUÇÃO}

A maior parte da energia consumida no mundo provém do petróleo, do carvão e do gás natural. Com o esgotamento das fontes naturais de energia, especialmente as fósseis, além de sua impossibilidade de renovação, há uma motivação para o desenvolvimento de tecnologias que permitam utilizar fontes de energias renováveis e ecologicamente corretas (Conceição et al., 2005).

O biodiesel é um biocombustível de grande crescimento no Brasil e no mundo, a forma mais comum de obtenção deste combustível é por meio da reação dos óleos vegetais com metanol ou etanol, na presença de um catalisador, em processo químico conhecido como transesterificação. Os produtos desta reação são a mistura de ésteres etílicos ou metílicos de ácidos graxos, que compõe o próprio biodiesel e glicerina, cujo maior constituinte é o glicerol (Ministério do Desenvolvimento Agrário, 2015).

Devido ao crescimento da produção de biodiesel, de acordo com Costa (2010), cresce um fator preocupante: o destino do glicerol excedente, visto que para cada tonelada de biodiesel obtido são gerados cerca de $100 \mathrm{~kg}$ de glicerol, provocando efeitos adversos à economia do biodiesel. Neste contexto, teme-se que o excesso de glicerina produzida, a qual pode provocar um elevado nível de poluição, possa ser descartada de maneira irresponsável no ambiente. 
Além da preocupação ambiental, segundo Neto et al. (2000), se o processo de recuperação e aproveitamento dos subprodutos da produção de biodiesel (glicerina e catalisador) for otimizado, essa produção pode ser obtida a um custo competitivo em comparação com o preço comercial do óleo diesel, potencializando a situação econômica do biodiesel no mercado.

O grande obstáculo da utilização deste composto é a sua pureza, porque após a reação de transesterificação alguns resíduos do processo acabam misturados à glicerina, por conseguinte o produto obtido na verdade consiste de uma mistura de glicerol, álcool (metanol ou etanol), água, sais inorgânicos proveniente dos catalisadores (hidróxido de potássio ou sódio), mono, di e triglicerídeos que não reagiram completamente, ácidos graxos livres, ésteres metílicos e etílicos e outras substâncias que podem ser encontradas dependendo da natureza do óleo e da maneira com que o procedimento foi efetuado (Chun-Hui et al., 2008).

Nas diversas aplicações da glicerina como em remédios, alimentos, resinas alquídicas, polióis e explosivos, a pureza é de fundamental importância nos processos de síntese destes derivados, requerendo-se, preferencialmente, teores entre 80 a $95 \%$ e, em torno 99,5\%, no caso da chamada glicerina técnica e na aplicada na indústria farmacêutica (Salvador et al., 2006).

Dentre todos os processos de purificação existentes, a escolha do melhor deles deve ser feita, portanto é necessária uma caracterização detalhada da amostra bem como as características que devem estar dentro das normas regulamentadoras para utilização da mesma. Dessa forma o seguinte trabalho tem por objetivo a caracterização da glicerina oriunda da transesterificação etílica do óleo de soja bruto e comparação com uma glicerina PA, para seleção de fatores que devem ser melhorados a fim de atingir-se um potencial analítico.

\section{MATERIAS E MÉTODOS}

Os reagentes utilizados foram óleo de soja bruto, fornecido pela COCAMAR, etanol anidro (99,8 $8^{\circ}$ INPM) adquirido da Usina Cocafé (Astorga, Paraná), hidróxido de sódio PA Biotec $\AA$ e glicerina PA Chemco ltda.

As caracterizações do óleo de soja bruto foram: índice de acidez e índice de saponificação segundo o método apresentado pelo Instituto Adolfo Lutz (2008), massa específica aferida no densímetro digital da marca Anton Paar modelo DMA 5000 na temperatura de $30^{\circ} \mathrm{C}$, do Departamento de Física da Universidade Estadual de Maringá, teor de umidade obtida no equipamento Karl Fischer da marca Analyser, modelo Umidade Controle KF-1000, viscosidade feita em um reômetro digital da marca Brookfield modelo DV-III com spindle SC4-27 e velocidades rotacionais entre 10 e $220 \mathrm{rpm}$ na temperatura de $30^{\circ} \mathrm{C}$ e para a determinação dos ácidos graxos presentes no óleo foi utilizada a cromatografia a gás, a qual, foi utilizada um cromatógrafo da marca Varian, modelo CP-3800, com detector de ionização em chama (DIC), contendo uma coluna capilar específica para a separação de ésteres (BP - X70 - SGE) de $30 \mathrm{~m}$ x 0,25 mm.

A transesterificação etílica do óleo de soja foi feito de acordo com os melhores resultados do trabalho de Gomes et al. (2013), que consiste na reação de óleo de soja com 


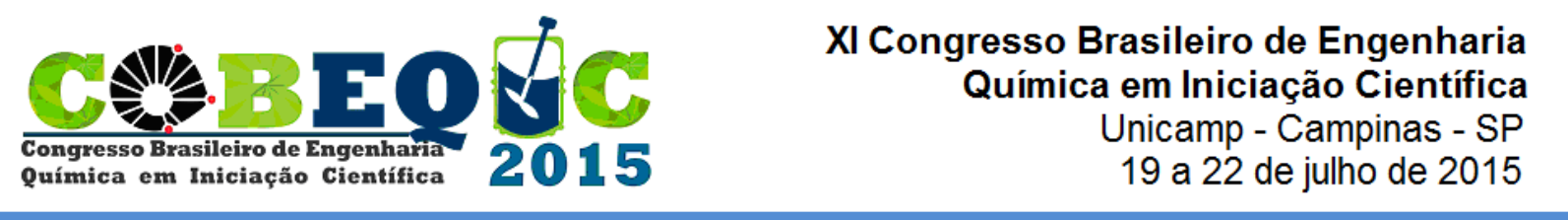

etanol em excesso à razão molar de 1:7,5 (óleo:ácool), a $30^{\circ} \mathrm{C}$, durante uma hora, sob agitação de $350 \mathrm{rpm}$ e com adição de hidróxido de sódio numa proporção de $1 \%$ mássico em relação à massa do óleo, a montagem do módulo experimental pode ser visualizada na Figura 1.

Figura 1 - Módulo experimental para produção de biodiesel.

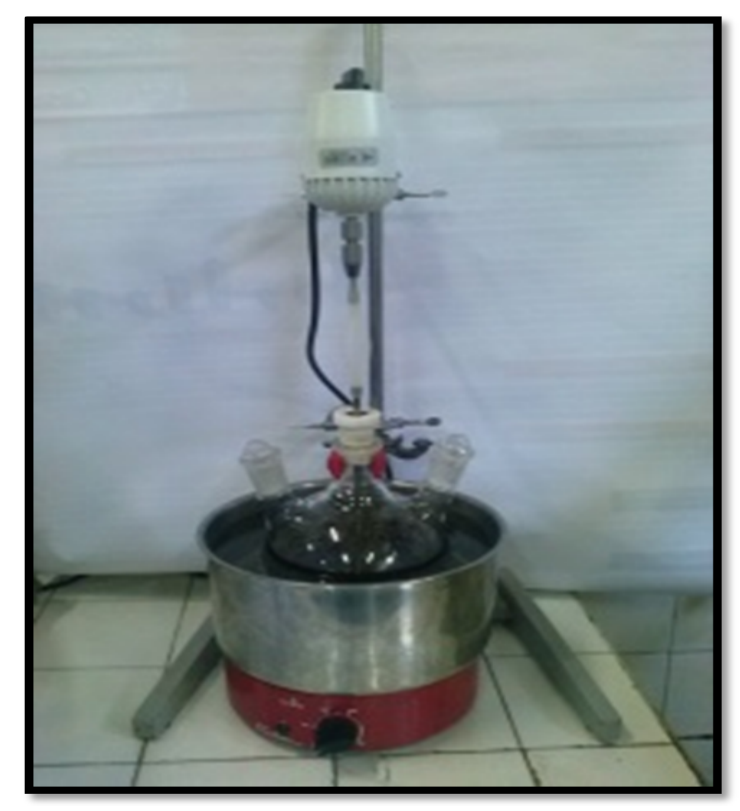

Após a reação, o produto reacional foi submetido à evaporação rotativa a $600 \mathrm{mmHg}$ de vácuo à $80^{\circ} \mathrm{C}$ durante 45 min para evaporação do álcool remanescente da reação. Feito isso, a mistura foi colocada em funil de separação e mantida em repouso até a decantação da fase rica em glicerol (fase mais densa), que foi separada para posteriores análises. É possível visualizar o processo descrito acima na Figura 2.

Figura 2 - Processo de separação da glicerina dos ésteres etílicos.

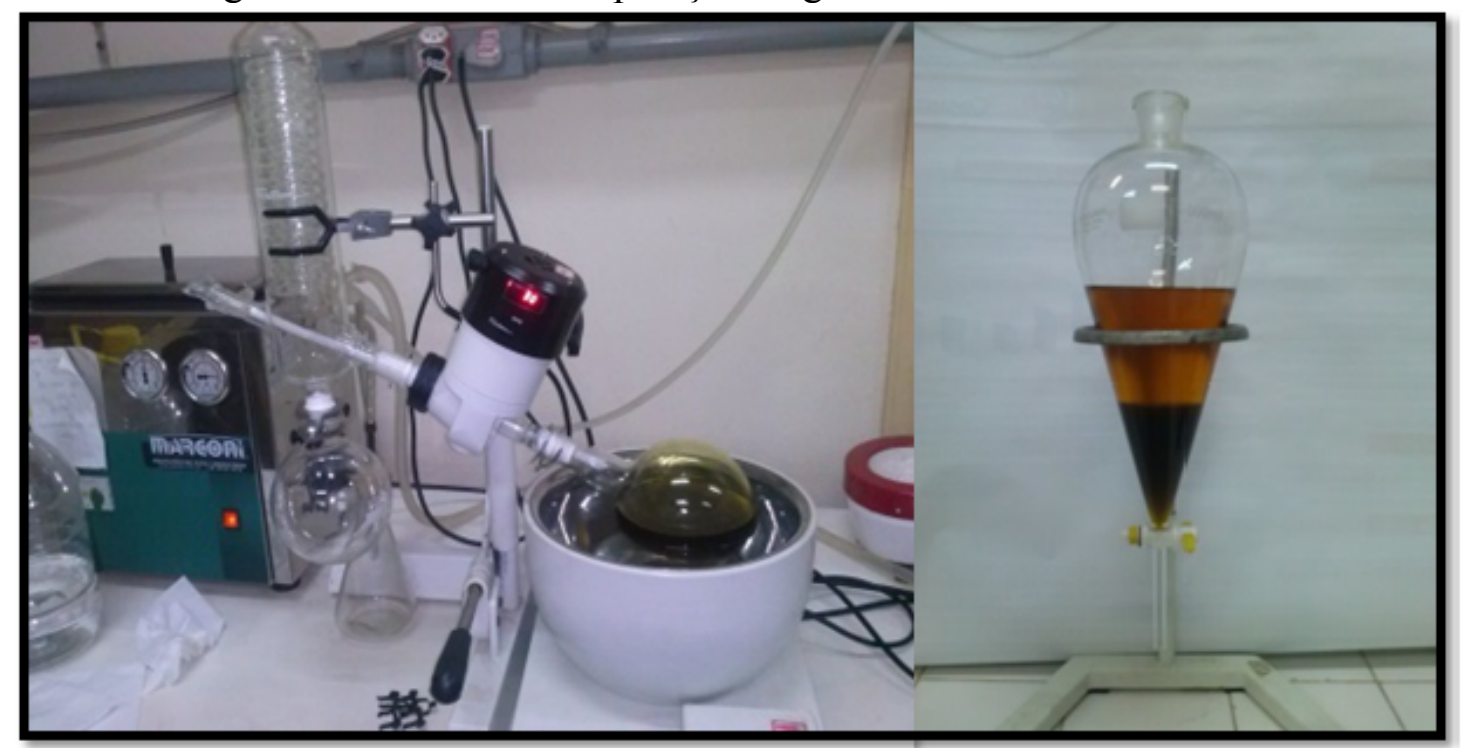


A fase rica em glicerol e a glicerina PA foram submetidas à análise do teor de glicerol pelo método do periodato de sódio, índice de acidez segundo o método apresentado pelo Instituto Adolfo Lutz (2008), massa específica aferida no densímetro digital da marca Anton Paar modelo DMA 5000 na temperatura de $30^{\circ} \mathrm{C}$, do Departamento de Física da Universidade Estadual de Maringá, teor de umidade obtida no equipamento Karl Fischer da marca Analyser, modelo Umidade Controle KF-1000, viscosidade feita em um reômetro digital da marca Brookfield modelo DV-III com spindle SC4-27 e velocidades rotacionais entre 10 e $220 \mathrm{rpm}$ na temperatura de $30^{\circ} \mathrm{C}$.

\section{RESULTADOS E DISCUSSÃO}

Na Tabela 1 são apresentados os resultados da caracterização do óleo de soja bruto:

Tabela 1 - Caracterização do óleo de soja bruto

\begin{tabular}{c|c|c|c}
\hline Análise & Resultado & Igreja (2013) & Reda (2010) \\
\hline Índice de saponificação (mgKOH/g óleo) & $189,94 \pm 0,35$ & - & 195 \\
Índice de Acidez (mgKOH/g óleo) & $2,60 \pm 0,03$ & - & 2,9 \\
Acidez (\%) & $1,31 \pm 0,02$ & 1,29 & 1,5 \\
Viscosidade Cinemática a $30^{\circ} \mathrm{C}\left(\mathrm{mm}^{2} / \mathrm{s}\right)$ & 46,73 & 24,87 & - \\
Densidade a $30^{\circ} \mathrm{C}\left(\mathrm{g} / \mathrm{cm}^{3}\right)$ & 0,91 & 0,87 & - \\
Umidade $(\%)$ & $0,16 \pm 0,01$ & 0,12 & - \\
\hline
\end{tabular}

Conforme expresso na Tabela 1 , temos os resultados dos índices de saponificação, acidez e umidade, bem próximos aos da literatura, uma diferença na viscosidade cinemática e na densidade quando comparado com Igreja (2013), porém essa referência afirmou ter tido esses dois parâmetros abaixo da literatura a que comparou os resultados, portanto não significa que os resultados encontrados não estão fora do esperado.

Segue na Tabela 2 a composição percentual dos ácidos graxos presente no óleo analisado:

Tabela 2 - Caracterização do óleo de soja bruto

\begin{tabular}{c|c|c}
\hline Ácidos graxos & Percentual & Gomes (2013) \\
\hline Ácido Mirístico (C14:0) & 7,7 & 12,1 \\
Ácido Palmítico (C16:0) & 7,8 & \\
Ácido Palmitoléico (C16:1) & 8,3 & 4,2 \\
Ácido Esteárico (C18:0) & 3,2 & 25,5 \\
Ácido Oleico (C18:1n9c) & 13,1 & 51,0 \\
Ácido Linoleico (C18:2n6c) & 26,9 & \\
Ácido Araquídico (C20:0) & 4,2 & \\
Ácido cis-11,14-Eicosênóico (C20:1) & 3,3 & 6,1 \\
Ácido Linolênico (C18:3n3) & 14,6 & \\
Ácido Behênico (C22:0) & 10,7 & \\
\hline
\end{tabular}


Os ácidos graxos encontrados no óleo em maior concentração foram o linoleico e o oleico, como é expresso na Tabela 2, o que era esperado, por se tratarem de ácidos graxos característicos do óleo de soja bem como principais ácidos graxos encontrados por Gomes (2013).

Seguem na Tabela 3 os resultados da caracterização da glicerina produzida e a PA:

Tabela 3 - Caracterização da glicerina produzida e PA

\begin{tabular}{c|c|c}
\hline Análise & Glicerina produzida & Glicerina PA \\
\hline Acidez $(\%)$ & $0,00 \pm 0,01$ & $0,26 \pm 0,22$ \\
Densidade a $30^{\circ} \mathrm{C}\left(\mathrm{g} / \mathrm{cm}^{3}\right)$ & 1,02 & 1,26 \\
Umidade $(\%)$ & $2,39 \pm 0,10$ & $1,32 \pm 0,01$ \\
$\mathrm{pH}$ & $10,57 \pm 0,09$ & $3,98 \pm 0,03$ \\
Teor de glicerol $(\%)$ & $38,5 \pm 0,4$ & $96,3 \pm 0,4$ \\
\hline
\end{tabular}

Como o objetivo é purificar a glicerina produzida até garantir potencial analítico, foram analisados os parâmetros de ambas para posteriormente buscar metodologia de levar os parâmetros da glicerina produzida aos da analítica.

Pela Tabela 3 pode-se dizer que a acidez de ambas as glicerinas estão próximas a zero. Já a densidade da glicerina PA está maior que a produzida, muito provavelmente, pois esta ainda possui ésteres, ácidos graxos e umidade que são menos densos que $1,26 \mathrm{~g} / \mathrm{cm}^{3}$. O pH da glicerina produzida é bem maior ${ }_{2}$ fato de a reação de transesterificação etílica do óleo de soja ter sido feita em meio básico garantindo $\mathrm{pH}$ maior que 7. Com relação ao teor de glicerol $(38,5 \%)$, principal indicador de pureza da glicerina, está baixo devido às várias impurezas oriundas da reação e da fraca separação dos ésteres produzidos. É preferível que esse teor chegue ao máximo possível, uma vez que para o setor farmacêutico, por exemplo, o requerido é $99,5 \%$.

Outro fator observado é a cor, tendo em vista que a glicerina produzida tem a coloração marrom escura e a PA transparente, tornando, portanto, a cor como outro fator para ser modificado com a purificação. Na Figura 3 são apresentadas fotografias representativas da diferença entre as cores destas duas glicerinas.

Figura 3 - Glicerina PA e produzida, respectivamente, à esquerda e à direita.

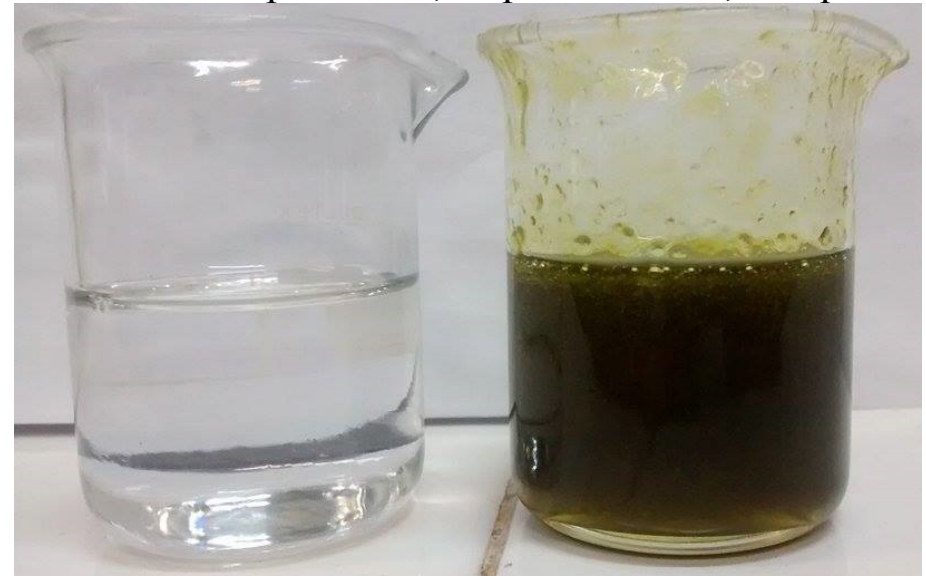




\section{CONCLUSÃO}

Pode-se então concluir que a glicerina oriunda da transesterificação etílica do óleo de soja bruto está longe de estar com potencial analítico, principalmente nos quesitos de teor de glicerol, $\mathrm{pH}$ e cor, porém essa glicerina tem potencial para ser purificada afim de adquirir maior valor agregado.

\section{AGRADECIMENTOS}

O presente trabalho foi realizado com o apoio do Conselho Nacional de Desenvolvimento Científico e Tecnológico - CNPq - Brasil.

\section{REFERÊNCIAS}

CHUN-HUI, C. Z.; BELTRAMINI, J. N.; FAN, Y.; LU, M. Q. Chemoselective Catalytic Conversion of Glycerol as a Biorenewable Source to Valuable Commodity Chemicals. Chemical Society Reviews, n. 37, p. 527-549, 2008.

CONCEIÇÃO, M. M.; CANDEIA, R. A.; DANTAS, H. J.; SOLEDADE, L. E. B.; FERNANDES Jr., V. J.; SOUZA, A. G. Rheological Behavior of Castor Oil Biodiesel. Energy and Fuels, v. 19, p. 2185-2188, 2005.

COSTA, J. B.; Produção biotecnológica de hidrogênio, etanol e outros produtos a partir do glicerol da reação de formação de biodiesel Dissertação de mestrado, Universidade Federal do Rio Grande do Sul, 2010.

INSTITUTO ADOLFO LUTZ. Métodos físico-químicos para análise de alimentos. $4^{\mathrm{a}}$ ed. São Paulo: Instituto Adolfo Lutz, 2008.

GOMES, M. C. S.; ARROYO, P. A.; PEREIRA, N. C. Influence of acidified water addition on the biodiesel and glycerol separation through membrane technology. Journal of Membrane Science. v. 431, p. 28-36, 2013.

IGREJA, G. da, Análise da purificação de biodiesel etílico de óleos de soja por ultrafiltração. Dissertação (Mestrado em Engenharia Química). Universidade Estadual de Maringá, Maringá, 2013.

MINISTÉRIO DO DESENVOLVIMENTO AGRÁRIO. DOSSIE BIODIESEL. Disponível em: < http://sistemas.mda.gov.br/condraf/arquivos/1372414257.pdf >. Acesso em: 25 fev. 2015

NETO, P. R. C.; ROSSI, L. F. S.; ZAGONEL, G. F. e RAMOS, L. P. Produção de biocombustível alternativo ao óleo diesel através da transesterificação de óleo soja usado em frituras. Química Nova, v. 23, n. 4, 2000.

SAlVADOR, Á. F.; MACHADO, A. S.; SANTOS, E. P.; Purificação da Glicerina Bruta Vegetal. In: I Congresso da Rede Brasileira de Tecnologia do Biodiesel, 2006, Brasília. 